\section{Original Article}

Korean J Transplant 2020;34:154-166 https://doi.org/10.4285/kjt.2020.34.3.154

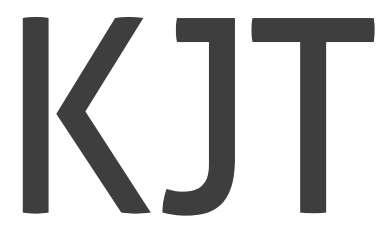

pISSN 2671-8790

elSSN 2671-8804

\title{
Clinical outcomes of the first 300 cases of kidney transplantation: a single-center retrospective cohort study
}

\author{
Hyoung Won Koh ${ }^{1}$, Kyunglim Koo ${ }^{1}$, Chang Sik Shin ${ }^{1}$, Hyung Sub Park ${ }^{1,2}$, \\ Jong Cheol Jeong ${ }^{3}$, Sejoong $\mathrm{Kim}^{3}$, Dong Wan $\mathrm{Chae}^{3}$, Jong Jin $\mathrm{Oh}^{4}$, \\ Seok-Soo Byun ${ }^{4}$, Taeseung Lee Le, $^{1,2}$ \\ ${ }^{1}$ Department of Surgery, Seoul National University Bundang Hospital, Seongnam, Korea \\ ${ }^{2}$ Department of Surgery, Seoul National University College of Medicine, Seoul, Korea \\ ${ }^{3}$ Department of Internal Medicine, Seoul National University Bundang Hospital, Seoul National University College \\ of Medicine, Seongnam, Korea \\ ${ }^{4}$ Department of Urology, Seoul National University Bundang Hospital, Seoul National University College of Medicine, \\ Seongnam, Korea
}

Received June 26, 2020

Revised August 16, 2020

Accepted August 17, 2020

Corresponding author: Taeseung Lee Department of Surgery, Seoul National University Bundang Hospital, 82 Gumiro 173beon-gil, Bundang-gu, Seongnam 13620 , Korea

Tel: +82-31-787-7999

Fax: +82-31-787-4055

E-mail: tslee@snubh.org

(c) The Korean Society for Transplantation This is an Open Access article distributed under the terms of the Creative Commons Attribution Non-Commercial License (http://creativecommons.org/licenses/ by-nc/4.0/) which permits unrestricted non-commercial use, distribution, and reproduction in any medium, provided the original work is properly cited.
Background: Kidney transplantation (KT) is regarded as the most effective treatment for end-stage renal disease. The annual number of KT cases in South Korea has increased rapidly as more centers are implementing a transplantation program. The objective of this study was to determine clinical outcomes of the first 300 consecutive cases of KT in a single center.

Methods: Clinical data of 300 cases of KT at Seoul National University Bundang Hospital from January 2004 to March 2018 were obtained from a prospectively collected database and retrospectively reviewed.

Results: The mean age of patients was $47.7 \pm 12.9$ years, and $59 \%$ of patients were male. There were 225 living donors and 75 deceased donors. A total of 42 cases were from ABO-incompatible donors. During a mean follow-up of $68.6 \pm 43.5$ months, 38 patients (12.7\%) experienced rejection. The most common cause was acute T-cell mediated rejection (9.0\%). Eighteen patients experienced graft loss. One-year and 5-year death-censored graft survival rates were $99 \%$ and $96.6 \%$, respectively. One-year and 5-year patient survival rates were $98.3 \%$ and $96.6 \%$, respectively. Multivariate analysis revealed that graft weight-to-recipient weight ratio and rejection were significant factors affecting graft survival.

Conclusions: This single-center review demonstrates clinical outcomes comparable to other major centers. Such good outcomes were obtained by good patient selection, dedicated transplant physicians, and adequate use of immunosuppressive therapy.

Keywords: Transplantation; Kidney transplantation

\section{INTRODUCTION}

The first kidney transplantation in South Korea was performed in 1969. The significant benefit of kidney trans- plantation over dialysis in terms of quality of life and life expectancy has led to a rapid rise in transplant cases nationwide to over 2,100 cases annually in 2018. Despite the increase of transplant cases, the number of patients on 


\section{HIGHLIGHTS}

- This study reports clinical outcomes of the first 300 consecutive cases of kidney transplantation at a single low-volume center.

- Our center has performed 300 cases of kidney transplantation over a period of 14 years since its first case in 2005 and is now performing $>50$ cases per year.

- One-year and 5-year death-censored graft survival rates were $99 \%$ and $96.6 \%$, respectively.

- One-year and 5-year patient survival rates were $98.3 \%$ and $96.6 \%$, respectively.

- Clinical outcomes up to date are comparable to prior reports from other leading centers.

the waiting list is increasing more rapidly each year due to the increased prevalence of chronic kidney disease [1,2]. Approaches to increase potential donor groups such as ABO-incompatible (ABOi) donors [3], extended criteria donors (ECD) [4], and donation after cardiac death (DCD) [5,6] are being implemented to overcome the organ shortage problem. Outcomes of these approaches have been shown to be acceptable compared to donation after brain death (DBD) and are superior to waiting for a DBD kidney [7]. Nonetheless, the mean time for waiting has continuously increased because organ demand has far exceeded organ supply. Despite an organ shortage, the number of kidney transplant cases performed nationwide and the number of centers performing kidney transplantation have increased with many new centers performing less than 50 cases per year. Cases performed at large-volume centers still constitute over $50 \%$ of total transplantation cases in South Korea up to date, although the number of cases performed by low-volume centers is constantly increasing [1].

Prior reports on clinical outcomes of kidney transplantation had mostly been published by large-volume centers that had started kidney transplantation before the turn of the millennium. In addition, most of these reports were published in the early 2000s [8-10]. Since there have been many updates in the field of transplantation, clinical outcomes from a medium-sized center that has recently started kidney transplantation can be noteworthy, although not entirely new.

The first case of kidney transplantation in Seoul National University Bundang Hospital (SNUBH) was performed in 2005. The number of cases gradually increased afterwards, from 12 cases in 2005 to 52 cases in 2018 . We herein describe our experience with the first 300 consecutive cases of kidney transplantation with the aim to determine and share clinical outcomes in terms of complications, graft survival, and patient survival. Independent factors affecting graft survival were also determined.

\section{METHODS}

This retrospective analysis was conducted in compliance with principles of the Declaration of Helsinki. This study was approved by the Institutional Review Board of Seoul National University Bundang Hospital, Korea (IRB No. B-2006-616-123).

\section{Data Collection}

Clinical records of 300 patients who underwent kidney transplantation at Seoul National University Bundang Hospital from January 2005 to March 2018 were reviewed. Data included age, sex, etiology, complication, relationship between donor and recipient, number of cases per year, graft survival, patient survival, and follow-up data after kidney transplantation. Data and statistics regarding kidney transplantation were obtained from the Korean Network for Organ Sharing (KONOS) annual report [1].

\section{Immunosuppressive Agents}

Induction immunosuppressive therapy was performed in $245(81.6 \%)$ cases. Our main induction agent was the anti-IL2 receptor antibody basiliximab (Simulect; Novartis, Basel, Switzerland), which was used in 235 patients (78.3\%) (20 mg administered on Days 0 and 4), while in 10 (3.3\%) selected high-risk patients, anti-thymocyte globulin (ATG; Fresenius Biotech, Grafelfing, Germany) was used and maintained for 3 days (Table 1). These selected highrisk patients had one or more of the following factors: (1) more than four human leukocyte antigen (HLA) mismatches, (2) more than 2 HLA class II (DR) mismatches, (3) positive reaction in flow-cytometric crossmatch test, (4) more than $30 \%$ of most recent pretransplant panel reactive antibody, (5) presence of pretransplant donor-specific antibody, (6) deceased donor kidney transplantation (DDKT), and (7) retransplantation. Cytomegalovirus (CMV) antigenemia or CMV quantitative polymerase chain reaction (PCR) was performed to monitor CMV titer when ATG was used 
Table 1. Patient demographics

\begin{tabular}{|c|c|c|c|}
\hline Variable & $\begin{array}{l}\text { Living donor } \\
\qquad(n=225)\end{array}$ & $\begin{array}{l}\text { Deceased donor } \\
\qquad(n=75)\end{array}$ & P-value \\
\hline \multicolumn{4}{|l|}{ Sex } \\
\hline Recipient & & & 0.015 \\
\hline Male & $142(63.1)$ & $35(46.7)$ & \\
\hline Female & $83(36.9)$ & $40(53.3)$ & \\
\hline Donor & & & 0.005 \\
\hline Male & $100(44.4)$ & $48(64.0)$ & \\
\hline Female & $125(55.6)$ & $27(36.0)$ & \\
\hline \multicolumn{4}{|l|}{ Age (yr) } \\
\hline Recipient & $46.4 \pm 13.2$ & $51.7 \pm 11.3$ & 0.002 \\
\hline Donor & $42.4 \pm 11.8$ & $46.7 \pm 13.6$ & 0.008 \\
\hline Etiology & & & 0.097 \\
\hline $\mathrm{DM}$ & $58(25.8)$ & $20(26.7)$ & \\
\hline $\mathrm{GN}$ & $51(22.7)$ & $22(29.3)$ & \\
\hline $\lg A$ & $40(17.8)$ & $0(0.0)$ & \\
\hline HTN & $23(10.2)$ & $6(8.0)$ & \\
\hline ADPKD & $10(4.4)$ & $5(6.7)$ & \\
\hline FSGS & $8(3.6)$ & $2(2.7)$ & \\
\hline Reflux & $4(1.8)$ & $1(1.3)$ & \\
\hline Others ${ }^{a)}$ & $9(4.0)$ & $3(4.0)$ & \\
\hline Unknown & $22(9.8)$ & $17(22.7)$ & \\
\hline \multicolumn{2}{|c|}{ Pretransplant renal replacement } & & $<0.001$ \\
\hline Hemodialysis & $131(58.2)$ & $51(68.0)$ & \\
\hline Peritoneal dialysis & $13(5.8)$ & $19(25.8)$ & \\
\hline No dialysis & $81(36.0)$ & $5(6.7)$ & \\
\hline Mean duration (mo) & 7.87 & 84.14 & $<0.001$ \\
\hline \multicolumn{4}{|l|}{ Donor-recipient relation } \\
\hline Living, related & $151(67.1)$ & & \\
\hline Sibling & $64(42.4)$ & & \\
\hline Offspring & $50(33.1)$ & & \\
\hline Parent & $28(18.5)$ & & \\
\hline Others & $9(6.0)$ & & \\
\hline Living, unrelated & $74(32.9)$ & & \\
\hline Spouse & $71(95.9)$ & & \\
\hline Others & $3(4.1)$ & & \\
\hline ABO compatibility & & & $<0.001$ \\
\hline ABO-compatible & $183(81.3)$ & $75(100.0)$ & \\
\hline ABO-incompatible & $42(18.7)$ & $0(0.0)$ & \\
\hline HLA mismatch & & & 0.022 \\
\hline 0 & $22(9.8)$ & $10(13.3)$ & \\
\hline 1 & $15(6.7)$ & $1(1.3)$ & \\
\hline 2 & $32(14.2)$ & $5(6.7)$ & \\
\hline 3 & $70(31.1)$ & $21(28.0)$ & \\
\hline 4 & $28(12.4)$ & $21(28.0)$ & \\
\hline 5 & $39(17.3)$ & $13(17.3)$ & \\
\hline 6 & $18(8.0)$ & $4(5.3)$ & \\
\hline
\end{tabular}

Table 1. Continued

\begin{tabular}{|c|c|c|c|}
\hline Variable & $\begin{array}{l}\text { Living donor } \\
\qquad(n=225)\end{array}$ & $\begin{array}{l}\text { Deceased donor } \\
\qquad(\mathrm{n}=75)\end{array}$ & P-value \\
\hline \multicolumn{3}{|l|}{ Immunosuppression } & $<0.001$ \\
\hline \multicolumn{4}{|l|}{ Induction agent } \\
\hline No & $50(22.2)$ & $5(6.7)$ & \\
\hline Simulect & $171(76.0)$ & $64(85.3)$ & \\
\hline ATG & $4(1.8)$ & $6(8.0)$ & \\
\hline \multicolumn{4}{|l|}{ Maintenance agent } \\
\hline Calcineurin inhibitor & \multirow[b]{2}{*}{$177(78.7)$} & & $<0.001$ \\
\hline Tacrolimus & & 73 (97.3) & \\
\hline Cyclosporin A & $48(21.3)$ & $2(2.7)$ & \\
\hline \multicolumn{2}{|l|}{ Antimetabolite } & & 0.898 \\
\hline Mycophenolate mofetil & $185(82.2)$ & $61(81.3)$ & \\
\hline Mycophenolic acid & 40 (17.8) & $14(18.7)$ & \\
\hline Prednisolone & $225(100.0)$ & $75(100.0)$ & - \\
\hline \multicolumn{3}{|c|}{ Desensitization for ABOi-KT recipient $\quad 42(100.0)$} & \\
\hline Rituximab & \multicolumn{2}{|c|}{$42(100.0)$} & \\
\hline Plasmapheresis & \multicolumn{2}{|c|}{$38(90.5)$} & \\
\hline \multicolumn{4}{|l|}{ Initial anti-A/B titers ${ }^{\mathrm{b})}$} \\
\hline $\lg G$ & \multicolumn{2}{|c|}{$1: 16(1: 2-1: 256)$} & \\
\hline $\lg \mathrm{M}$ & \multicolumn{2}{|c|}{$1: 8(1: 1-1: 128)$} & \\
\hline \multicolumn{4}{|l|}{ Preoperative anti-A/B titer ${ }^{\mathrm{b})}$} \\
\hline $\lg G$ & \multicolumn{2}{|c|}{ 1:4 (negative-1:16) } & \\
\hline $\lg M$ & \multicolumn{2}{|c|}{ 1:1 (negative-1:4) } & \\
\hline
\end{tabular}

Values are presented as number (\%) or mean \pm standard deviation.

DM, diabetes mellitus; GN, glumerulonephritis; Ig, immunoglobulin; HTN, hypertension; ADPKD, autosomal dominant polycystic kidney disease; FSGS, focal segmental glumerulosclerosis; HLA, human leukocyte antigen; $A T G$, anti-thymocyte globulin; $A B O \mathrm{O}-\mathrm{KT}, \mathrm{ABO}$-incompatible kidney transplantation.

a) Others include Wilms' tumor (1 case), lupus nephritis (3 cases), Alport syndrome ( 2 cases), drug toxicity ( 1 case), renal agenesis ( 1 case), Henoch-Schonlein nephritis (1 case), Hantaan virus infection (1 case),

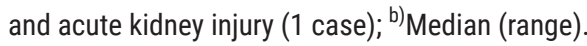

as induction agent.

Initial maintenance immunosuppressive agents included calcineurin inhibitors, antimetabolites, and corticosteroids. All agents were started two days prior to transplantation for living donors and on the day of transplantation for deceased donors. Calcineurin inhibitors were administered at a dose of $0.07 \mathrm{mg} / \mathrm{kg}$ for tacrolimus (Prograf; Astellas Pharma Inc., Toyama, Japan) or $3 \mathrm{mg} /$ $\mathrm{kg}$ for cyclosporine (Sandimmune; R.P. Scherer, Eberbach, Germany) twice a day. Tacrolimus was adjusted to a target level of $9-13 \mathrm{ng} / \mathrm{mL}$ and cyclosporine was adjusted to 
a target level of $300 \mathrm{ng} / \mathrm{mL}$ until postoperative 4 weeks. In cases that used ATG as the induction agent, tacrolimus dosage was reduced to $0.035 \mathrm{mg} / \mathrm{kg}$ during ATG use. As an antimetabolite, 500-750 mg of mycophenolate mofetil (CellCept; F. Hoffmann-La Roche, Basel, Switzerland), or 360-540 mg of mycophenolic acid (Myfortic, Novartis) was administered twice a day. Intravenous methylprednisolone was tapered to a dose of $20 \mathrm{mg}$ per day on postoperative day 6 . This dosage was maintained until discharge.

\section{Infection Prophylaxis}

To prevent bacterial infection, 1st generation cephalosporin was administered intravenously until postoperative day 3 and prior to invasive procedures including percutaneous intervention and biopsy. To prevent Pneumocystis jirovecii infection, trimethoprim/sulfamethoxazole $400 / 80 \mathrm{mg}$ (Septrin; Samil Pharm, Seoul, Korea) was administered for 6 months postoperatively. Nystatin gargle and chlorhexidine gargle were alternatively used to prevent fungal infection. For herpes prophylaxis, 400 mg of acyclovir (Zoylex; VHB Life Sciences, Mumbai, India) was administered orally for 4 weeks. In transplant pairs in which the donor was CMV IgG positive and the recipient negative, ganciclovir (Cymevene; Exela Pharma Sciences, Lenoir, NC, USA) was administered at a dose of $5 \mathrm{mg} / \mathrm{kg}$ during the hospital stay and subsequently $900 \mathrm{mg}$ of valganciclovir (Valcyte; Genentech, South San Francisco, CA, USA) was administered for 3 months.

A

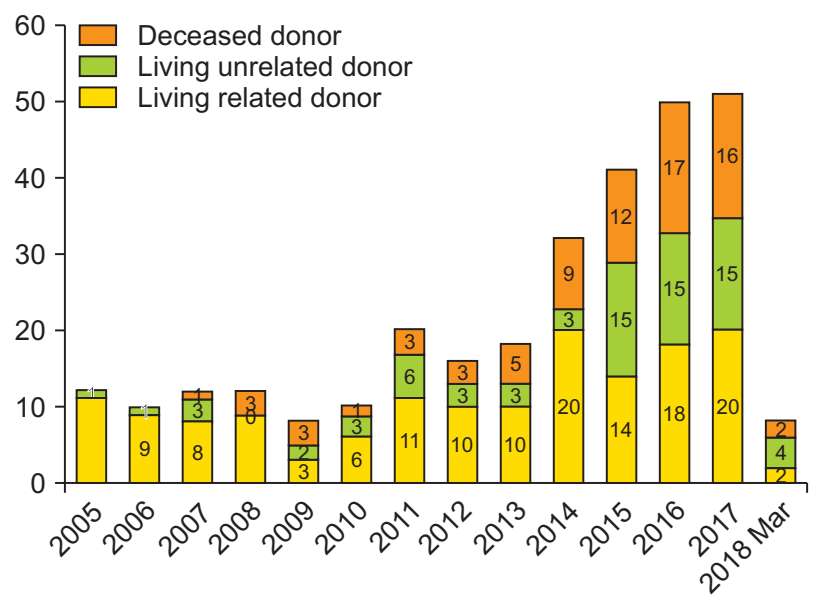

\section{Desensitization for ABO-Incompatible Kidney Transplantation}

Rituximab (MabThera, Genentech), plasmapheresis, and low-dose intravenous immunoglobulin (IVIG) infusion were used for desensitization. When plasmapheresis was not performed, $375 \mathrm{mg} / \mathrm{m}^{2}$ or $500 \mathrm{mg} / \mathrm{m}^{2}$ of rituximab was administered 2 weeks before initiation of plasmapheresis or before operation. Plasmapheresis was performed via a subcutaneous catheter. $A B O$ isoagglutinin immunoglobulin $M / G(\mathrm{IgM} / \mathrm{G})$ titers were checked before and after each plasmapheresis session and at 1 week before the operation, and our target isoagglutinin titer was 1:8. After plasmapheresis, $100 \mathrm{mg} / \mathrm{kg}$ of IVIG infusion was administered. Post-transplant plasmapheresis was performed when the post-transplant isoagglutinin titer was higher than 1:32, which was checked every 2 days.

\section{Rejection}

Rejection was suspected when a patient's serum creatinine level did not show adequate decline postoperatively or became elevated without other possible causes such as dehydration or infection. Renal biopsy was performed in such cases under the guidance of ultrasonography. Borderline changes that were not consistent with serum creatinine levels were considered subclinical rejection, and in such cases, no specific treatment was used. Steroid pulse therapy was started before biopsy results were obtained when rejection was highly suspected clinically. Biopsy-proven acute rejections were treated primarily by using steroid pulse therapy, while ATG antibody was adminis-

B

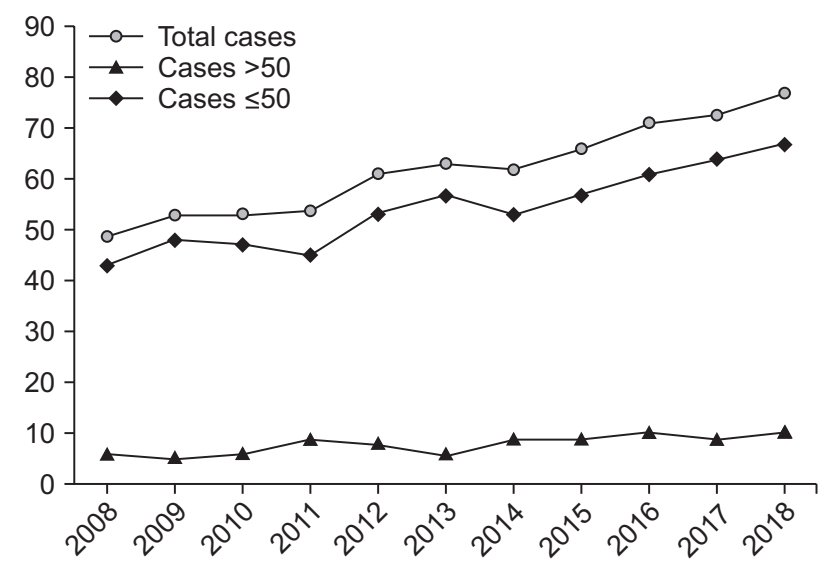

Fig. 1. Statistics. (A) Annual number of kidney transplantations in Seoul National University Bundang Hospital. (B) Number of centers performing kidney transplantation in South Korea. Circle, total number of centers performing kidney transplantation; triangle, large-volume centers performing more than 50 cases annually; diagonal, small centers performing 50 cases or less annually. 
tered when patients were found to be refractory to steroid treatment. When B-cell mediated rejection was confirmed, IVIG and/or plasmapheresis was given.

\section{Statistics}

All statistical analyses were performed using IBM SPSS ver. 22.0 (IBM Corp., Armonk, NY, USA). Patient survival and graft survival were computed according to the Kaplan-Meier method. Univariate and multivariate analyses were performed using Cox regression to estimate prognostic factors for graft survival and patient survival. A $P$-value of less than 0.05 was considered significant.

\section{RESULTS}

The first kidney transplantation in SNUBH was performed in 2005. The number of kidney transplantation cases in 2005 was 12 (11 living related donors and one living unrelated donor). The first DDKT was performed in 2007. Fig. 1A demonstrates the number of kidney transplantation cases performed in SNUBH from 2005 to March 2018. The number of cases per year increased from 12 in 2005 to 51 in 2017. Fig. 1B shows the number of transplant cases performed at large and smaller volume centers. The number of cases performed at large-volume centers has shown little increase, whereas those at smaller centers is showing rapid growth.

\section{Patient Characteristics}

Characteristics of the first 300 patients included in this study are shown in Table 1. Among these 300 cases, 225 (75\%) were living donor kidney transplantation (LDKT) and $75(25 \%)$ were DDKT. Of these 300 cases, 177 recipients $(59 \%)$ were male and 123 recipients $(41 \%)$ were female. Of the 300 donors, 148 (49.3\%) were male and 152 (50.7\%) were female. Regarding the etiology, diabetic nephropathy
A

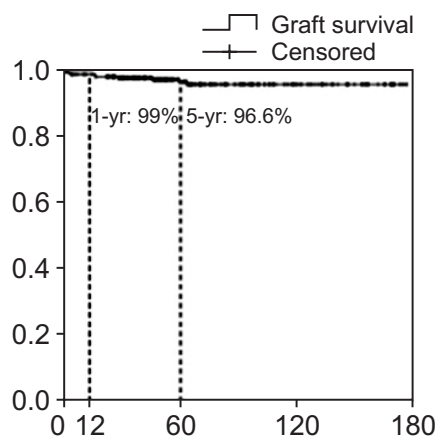

B

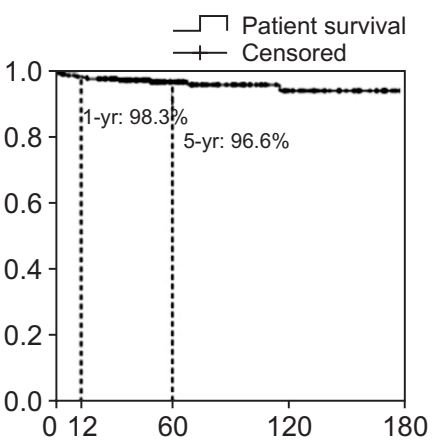

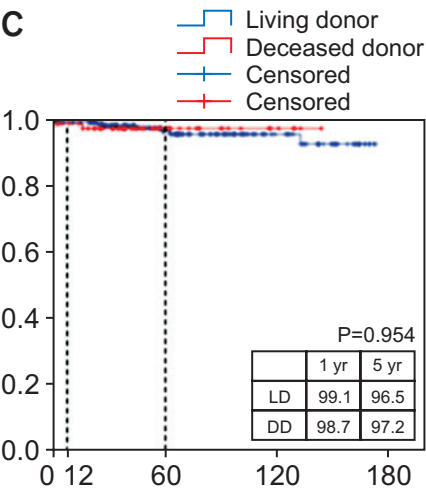
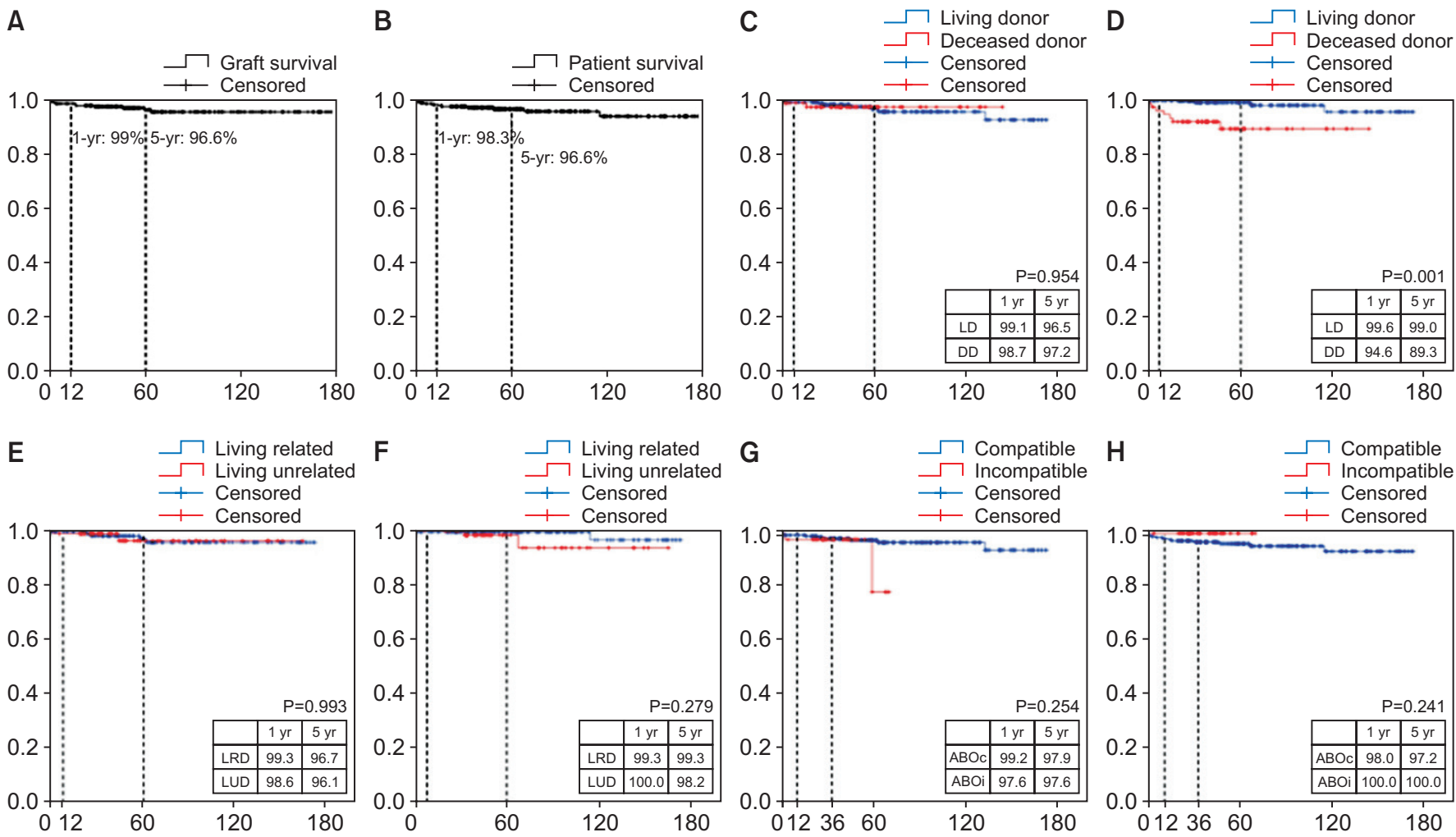

Fig. 2. Graft survival and patient survival after kidney transplantation. (A) Death-censored graft survival and (B) survival in 300 cases of kidney transplantation. (C) Death-censored graft survival and (D) patient survival of living donors and deceased donors. (E) Death-censored graft survival and (F) patient survival of living related donors and living unrelated donors. $(G)$ Death-censored graft survival and $(H)$ patient survival of $A B O$-compatible pairs and $A B O$-incompatible pairs. LD, living donor; $D D$, deceased donor; LRD, living related donor; LUD, living unrelated donor; $A B O c$, $A B O-c o m p a t i b l e ; A B O i$, ABO-incompatible. 
accounted for the highest percentage (78 cases, $26 \%$ ), followed by glomerulonephritis (73 cases, $24.3 \%$ ) and IgA nephropathy (40 cases, $13.3 \%$ ). Pretransplant renal replacement was performed for $214(71.3 \%)$ recipients. The mean duration of pretransplant renal replacement was 7.87 months for LDKT recipients and 84.14 months for DDKT recipients. Regarding HLA matching, $7.3 \%$ of transplant pairs had full HLA match while $10.7 \%$ of them had total mismatch. For induction therapy, basiliximab was administered in $235(78.3 \%)$ cases and ATG was administered in $10(3.3 \%)$ high-risk patients. All patients received triple maintenance immunosuppressive agents (calcineurin inhibitor, antimetabolite, and steroid).

\section{Living versus Deceased Donor Kidney Transplantation}

From 225 cases of LDKT, 151 cases were from living related donors and 74 cases were from living unrelated donors. Regarding donor-recipient relations, of the 151 cases of living related donors, 64 (42.4\%) were siblings, $50(33.1 \%)$ were offspring, and $28(18.5 \%)$ were parents. Among living unrelated donors, most donors were spouses (71 cases, $95.9 \%)$. Three were non-relative living donors. Of these three donors, two were exchange donors. No significant $(P=0.954)$ difference in outcome in terms of recipient graft survival was observed between living donors and deceased donors. However, 5-year patient survival was significantly higher in recipients receiving a kidney from a living donor compared to a deceased donor $(P=0.001)$ (Fig. $2 C$ and $D)$. There was no significant difference in graft survival $(P=0.993)$ (Fig. $2 E)$ or patient survival $(\mathrm{P}=0.279)$ (Fig. 2F) between living related donors and living unrelated donors. Since most living unrelated donors were spouses, no significant difference was observed in graft survival $(P=0.993)$ or patient survival $(P=0.279)$ between living related donors and spousal donors (data not shown).

\section{ABO-Incompatible Kidney Transplantation}

The first case of ABO-incompatible kidney transplantation (ABOi-KT) was performed in 2013. Since then, the annual number of cases has increased to 17 in 2017. The median follow-up period of ABOi-KT was 37.7 months (data not shown). Among the 42 cases of kidney transplantation with ABOi pairs, 22 (52.4\%), eight (19\%), seven (16.7\%), and five $(11.9 \%)$ cases of donors were spouse, offspring, siblings, and parents, respectively (data not shown). The mean number of HLA mismatch was $3.12 \pm 1.64$ in $\mathrm{ABO}$-compatible kidney transplantation (ABOC-KT) and
$3.52 \pm 1.82$ in $A B O i-K T(P=0.152$, data not shown). Initial anti-A/B antibody titer ranged from $1: 2$ to $1: 256$ with a median titer of 1:16 (Table 1). Except for five ABOi-recipients who did not receive plasmapheresis, the rest of the ABOi-recipients received rituximab, IVIG, and plasmapheresis. Preoperative anti-A/B antibody titer after desensitization ranged from negative to $1: 16$, with a median titer of 1:4 (Table 1). Regarding outcomes compared to ABOc-KT, 3-year graft survival rate and patient survival rate were analyzed since median follow-up after ABOi-KT was only 34 months. ABOi-KT showed no inferiority in terms of graft survival (1-year or 3-year, $P=0.254$ ) (Fig. 2G) and patient survival (1-year or 3-year, $P=0.241$ ) (Fig. $2 \mathrm{H}$ ).

Table 2. Postoperative complications within 4 weeks after kidney transplantation

\begin{tabular}{lc}
\hline \multicolumn{1}{c}{ Complication } & No. of patients (\%) \\
\hline Delayed graft function & $16(5.3)$ \\
Surgical & $26(8.7)$ \\
Bleeding & $13(4.3)$ \\
Lymphocele & $5(1.7)$ \\
Wound problem & $4(1.3)$ \\
Others ${ }^{\text {a) }}$ & $4(1.3)$ \\
Urological complication & $12(4)$ \\
Urine leak & $7(2.3)$ \\
Ureterovesical junction stenosis & $4(1.3)$ \\
Bladder fistula & $1(0.3)$ \\
Nonsurgical & $24(8)$ \\
Infection & $17(5.7)$ \\
Urinary tract infection & $15(5)$ \\
Others) & $2(0.7)$ \\
Gastrointestinal & $5(1.7)$ \\
Ulcer bleeding & $2(0.7)$ \\
Postoperative liver dysfunction & $2(0.7)$ \\
Ileus & $1(0.3)$ \\
Cardiovascular & $2(0.7)$ \\
Unstable angina & $1(0.3)$ \\
Stress-induced cardiomyopathy & $1(0.3)$ \\
Angiodysplasia of small bowel ${ }^{\mathrm{c})}$ & $1(0.3)$ \\
Mortality & $2(0.7)$ \\
Aspiration pneumonia & $1(0.3)$ \\
Bleeding & $1(0.3)$ \\
\hline
\end{tabular}

a) Others include each case of arterial thrombosis, arterial anastomosis dehiscence, surgery-related radiculopathy, and embolic infarction; ${ }^{\text {b) }}$ Others includes herpes esophagitis and bacteremia without infection focus; ${ }^{c}$ Angiodysplasia was pathologically confirmed in one patient. 
Table 3. Overall outcomes of kidney transplantation

\begin{tabular}{|c|c|}
\hline Characteristics & No. of recipients \\
\hline \multicolumn{2}{|l|}{ Infection } \\
\hline Bacteria & $79(26.3)$ \\
\hline Urinary tract infection & $66(26.3)$ \\
\hline Pneumonia & $7(2.3)$ \\
\hline Prostatitis & $3(1.0)$ \\
\hline Others ${ }^{a)}$ & $3(1.0)$ \\
\hline \multicolumn{2}{|l|}{ Bacterial pathogen } \\
\hline Escherichia coli & $35(11.7)$ \\
\hline Klebsiella pneumonia & $18(6.0)$ \\
\hline Enterococcus faecalis & $9(3.0)$ \\
\hline Enterococcus aerogenes & $3(1.0)$ \\
\hline Pseudomonas aeruginosa & $2(0.7)$ \\
\hline Other enterococcus & $2(0.7)$ \\
\hline Virus & $73(24.3)$ \\
\hline Cytomegalovirus & $32(10.7)$ \\
\hline BK virus & $22(7.3)$ \\
\hline Herpes zoster & $9(3.0)$ \\
\hline Influenza & $8(2.7)$ \\
\hline Parainfluenza & $1(0.3)$ \\
\hline HSV & $1(0.3)$ \\
\hline Fungus & $10(3.3)$ \\
\hline Pneumocystis jirovecii & $8(2.7)$ \\
\hline Others ${ }^{\text {b) }}$ & $2(0.7)$ \\
\hline \multicolumn{2}{|l|}{ Rejection } \\
\hline Suspected rejection & $54(18)$ \\
\hline Steroid pulse therapy & $45(15)$ \\
\hline Rituximab & $2(0.7)$ \\
\hline Anti-thymocyte antibody & $1(0.3)$ \\
\hline No treatment & $6(2)$ \\
\hline Biopsy proven & $38(12.7)$ \\
\hline Acute T-cell mediated & $27(9.0)$ \\
\hline Borderline & $8(2.7)$ \\
\hline Antibody mediated & $3(1.0)$ \\
\hline Malignancy & $8(2.7)$ \\
\hline Renal cell carcinoma ${ }^{\mathrm{c})}$ & $1(0.3)$ \\
\hline Cholangiocarcinoma & $1(0.3)$ \\
\hline Ductal carcinoma in situ of breast & $1(0.3)$ \\
\hline Medullary carcinoma of thyroid & $1(0.3)$ \\
\hline Papillary carcinoma of thyroid & $1(0.3)$ \\
\hline Kaposi sarcoma of skin & $1(0.3)$ \\
\hline Squamous cell carcinoma of skin & $1(0.3)$ \\
\hline Graft loss & $18(6.0)$ \\
\hline Death & $11(3.3)$ \\
\hline With function & $7(2.3)$ \\
\hline Noncompliance & $3(1.0)$ \\
\hline
\end{tabular}

Table 3. Continued

\begin{tabular}{lc}
\hline \multicolumn{1}{c}{ Characteristics } & No. of recipients \\
\hline Acute rejection & $2(0.7)$ \\
Infection & $1(0.3)$ \\
Renal artery thrombosis & $1(0.3)$ \\
Postoperative bleeding & $1(0.3)$ \\
Death & $11(3.7)$ \\
Infection & $4(1.3)$ \\
Cardiologic & $2(0.7)$ \\
Malignancy & $1(0.3)$ \\
Unknown & $2(0.7)$ \\
Others & d) \\
\hline
\end{tabular}

HSV, herpes simplex virus.

a) Others includes septic arthritis, Nocardiasis, and acute gastroenteritis;

b) Others includes lung abscess and cervicofacial actinomyces; ${ }^{c}$ Renal cell carcinoma was found in native kidney; ${ }^{d)}$ Others includes bleeding and ischemic colitis.

\section{Postoperative Complications after Kidney Transplantation} Postoperative complications were defined as adverse events that occurred within 4 weeks after operation (Table 2). Delayed graft function occurred in 16 cases (5.3\%). Surgical complications including bleeding, wound complication, lymphocele, arterial thrombosis, anastomosis dehiscence, surgery-related radiculopathy, perirenal fluid collection, and embolic infarction were observed in 26 cases (8.7\%). Urological complications including urine leak, ureteral or ureterovesical junction stenosis, and bladder fistula were observed in 12 cases (4.0\%). Nonsurgical complications including infections, gastrointestinal complications, and cardiovascular events occurred in 24 cases (8.0\%). There was a case of small bowel angiodysplasia that caused life-threatening bleeding, which was treated with thalidomide as reported previously [11]. Two deaths due to aspiration pneumonia and bleeding were observed within 4 weeks after operation.

\section{Outcomes and Complications}

Outcomes and complications at postoperative 4 weeks after kidney transplantation are shown in Table 3. Infection was the most common complication. Urinary tract infection was the leading cause of bacterial infection (66 cases), followed by pneumonia (7 cases) and prostatitis (3 cases). Other complications included septic arthritis, Nocardiosis, and acute gastroenteritis. Escherichia coli (35 cases), Klebsiella pneumonia (18 cases), Enterococcus faecalis (9 cases), and Enterococcus aerogenes (3 cases) 
were found to be the most common pathogens. The most common viral pathogen was CMV (32 cases), followed by BK virus (22 cases), varicella-zoster virus (9 cases), and influenza (8 cases). P. jirovecii infection was observed in eight patients. Other fungal infections including lung abscess and cervicofacial abscess were observed in two patients.

Rejection was suspected in 54 cases, of which 38 cases were biopsy proven. Acute cellular rejection was the most common type (71.1\%), followed by antibody mediated rejection (7.9\%). Among clinical rejections, a total of 48 patients underwent treatment. The most common treatment was steroid pulse therapy (45 patients), followed by administration of rituximab (2 patients) and anti-thymocyte antibody (1 patient). Among biopsy-proven rejections, 36 cases were rescued while two cases had graft failure due to acute cellular rejection and acute T-cell-mediated rejection, respectively.

Seven cases of de novo malignancy were found during follow-up, including ductal carcinoma in situ of the breast (1 case), cholangiocarcinoma (1 case), renal cell carcinoma (1 case), papillary carcinoma of the thyroid (1 case), medullary carcinoma of the thyroid ( 1 case), Kaposi sarcoma of the skin (1 case), and squamous cell carcinoma of the skin (1 case).

\section{Patient and Graft Survival}

During a median follow-up period of 52 months, graft failure was observed in 18 patients (Table 3 ). The most common cause was death, followed by noncompliance and acute rejection. Seven deaths were determined as death with functioning graft. Death-censored graft survival rates

Table 4. Independent risk factors affecting rejection

\begin{tabular}{|c|c|c|c|c|}
\hline \multirow{2}{*}{ Variable } & \multicolumn{2}{|c|}{ Univariate analysis } & \multicolumn{2}{|c|}{ Multivariate analysis } \\
\hline & $\mathrm{HR}(95 \% \mathrm{Cl})$ & P-value & $\mathrm{HR}(95 \% \mathrm{Cl})$ & P-value \\
\hline Donor age & $1.015(0.988-1.042)$ & 0.275 & & \\
\hline Donor sex (female) & $1.190(0.634-2.236)$ & 0.588 & & \\
\hline Deceased donor & $1.220(0.604-2.463)$ & 0.579 & & \\
\hline Recipient age & $1.014(0.989-1.040)$ & 0.267 & & \\
\hline \multicolumn{5}{|l|}{ Recipient medical history } \\
\hline Diabetes & $2.237(1.171-4.274)$ & 0.015 & $2.266(1.128-4.552)$ & 0.022 \\
\hline Hypertension & $1.050(0.460-2.401)$ & 0.907 & & \\
\hline Recipient sex (female) & $0.912(0.480-1.735)$ & 0.779 & & \\
\hline Dialysis & & 0.203 & & \\
\hline Hemodialysis & $1.409(0.651-3.050)$ & 0.384 & & \\
\hline Peritoneal dialysis & $2.567(0.910-7.236)$ & 0.075 & & \\
\hline Duration of dialysis & $1.003(0.997-1.009)$ & 0.387 & & \\
\hline Graft weight & $0.997(0.990-1.005)$ & 0.486 & & \\
\hline Gw/Rw ratio & $0.766(0.532-1.102)$ & 0.151 & & \\
\hline Number of graft artery & $0.879(0.485-1.591)$ & 0.670 & & \\
\hline Number of graft vein & $0.512(0.071-3.692)$ & 0.506 & & \\
\hline ABO incompatibility & $1.123(0.466-2.708)$ & 0.796 & & \\
\hline HLA mismatch & $1.173(0.964-1.428)$ & 0.111 & & \\
\hline Delayed graft function & $4.886(1.720-13.878)$ & 0.003 & & \\
\hline \multicolumn{5}{|c|}{ Postoperative complication } \\
\hline Surgical & $1.293(1.094-1.527)$ & 0.003 & & \\
\hline Urological & $7.622(1.965-29.567)$ & 0.003 & $4.595(0.964-21.900)$ & 0.056 \\
\hline Infectious & $7.480(2.716-20.601)$ & $<0.001$ & $5.243(1.7422-15.780)$ & 0.003 \\
\hline Bacterial infection & $1.843(0.939-3.619)$ & 0.076 & & \\
\hline Viral infection & $3.478(1.789-6.761)$ & $<0.001$ & $2.995(1.472-6.095)$ & 0.002 \\
\hline Malignancy & $2.255(0.424-11.987)$ & 0.340 & & \\
\hline
\end{tabular}

$\mathrm{HR}$, hazard ratio; $\mathrm{Cl}$, confidence interval; $\mathrm{Gw}$, graft weight; Rw, recipient weight; $\mathrm{HLA}$, human leukocyte antigen. 
at 1 year and 5 years were $99.0 \%$ and $96.6 \%$, respectively. Patient survival rates at 1 year and 5 years were $98.3 \%$ and $96.6 \%$, respectively (Fig. 2A and B). As of December 2019 , there were a total of 11 deaths during follow-up. The most common cause of death was infection, including two cases of pneumonia, one case of urinary tract infection, and one case of infective endocarditis. The second most common cause of mortality was cardiovascular event, including one case of hypertrophic myocarditis and one case of cardiac arrest. One death was due to malignancy (cholangiocarcinoma). Two deaths were due to an unknown cause. One death was due to bleeding and another death was due to ischemic colitis.

\section{Independent Risk Factors Affecting Rejection}

Univariate and multivariate analyses were performed to determine independent risk factors affecting rejection. Univariate analysis revealed that predisposing diabetes of the recipient, peritoneal dialysis, delayed graft function, postoperative surgical complication, postoperative urological complication, postoperative infectious complication, bacterial infection and viral infection were risk factors affecting rejection. In multivariate analysis, predisposing diabetes of the recipient, postoperative urological complication, postoperative infectious complication and viral infection were shown to be independent risk factors affecting rejection (Table 4).

Independent risk factors affecting each type of rejection were analyzed using univariate and multivariate

Table 5. Independent risk factors affecting death-censored graft survival

\begin{tabular}{|c|c|c|c|c|}
\hline \multirow{2}{*}{ Variable } & \multicolumn{2}{|c|}{ Univariate analysis } & \multicolumn{2}{|c|}{ Multivariate analysis } \\
\hline & $\mathrm{HR}(95 \% \mathrm{Cl})$ & P-value & $\mathrm{HR}(95 \% \mathrm{Cl})$ & P-value \\
\hline Donor age & $1.060(0.998-1.125)$ & 0.060 & $1.089(0.997-1.189)$ & 0.058 \\
\hline Donor sex (female) & $0.028(0.297-3.554)$ & 0.966 & & \\
\hline Deceased donor & $0.955(0.200-4.568)$ & 0.954 & & \\
\hline Recipient age & $0.987(0.940-1.036)$ & 0.596 & & \\
\hline \multicolumn{5}{|l|}{ Recipient medical history } \\
\hline Diabetes & $3.347(0.955-11.736)$ & 0.059 & & \\
\hline Hypertension & $0.278(0.080-0.970)$ & 0.045 & $0.248(0.05-1.122)$ & 0.070 \\
\hline Recipient sex (female) & $0.521(0.134-2.026)$ & 0.347 & & \\
\hline Dialysis & & 0.978 & & \\
\hline Hemodialysis & $1.101(0.275-4.410)$ & 0.891 & & \\
\hline Peritoneal dialysis & $0.899(0.093-8.670)$ & 0.927 & & \\
\hline Duration of dialysis & $0.999(0.983-1.015)$ & 0.912 & & \\
\hline Graft weight & $1.013(1.006-1.020)$ & $<0.001$ & & \\
\hline Gw/Rw ratio & $1.551(1.140-2.109)$ & 0.005 & $1.603(1.125-2.285)$ & 0.009 \\
\hline No. of graft artery & $0.929(0.311-2.777)$ & 0.894 & & \\
\hline No. of graft vein & $2.220(0.393-12.554)$ & 0.367 & & \\
\hline ABO incompatibility & $2.474(0.495-12.363)$ & 0.270 & & \\
\hline HLA mismatch & $0.936(0.647-1.354)$ & 0.726 & & \\
\hline Delayed graft function & $6.458(1.334-31.262)$ & 0.020 & & \\
\hline \multicolumn{5}{|c|}{ Postoperative complication } \\
\hline Surgical & $1.141(0.842-1.546)$ & 0.396 & & \\
\hline Urological & $0.047(0.000-530897.684)$ & 0.713 & & \\
\hline Infectious & $5.936(1.222-28.813)$ & 0.027 & & \\
\hline Bacterial infection & $1.046(0.268-4.076)$ & 0.948 & & \\
\hline Viral infection & $0.883(0.183-4.261)$ & 0.877 & & \\
\hline Rejection & $9.920(2.781-35.389)$ & $<0.001$ & $10.135(2.031-50.578)$ & 0.005 \\
\hline Malignancy & $0.048(0.000-24138133.42)$ & 0.766 & & \\
\hline
\end{tabular}

Gw, graft weight; Rw, recipient weight; HLA, human leukocyte antigen. 
analysis. Univariate analysis revealed that predisposing hypertension of the recipient, delayed graft function, postoperative surgical complication, postoperative urological complication, postoperative infectious complication, bacterial infection and viral infection were independent risk factors affecting acute T-cell mediated rejection. Multivariate analysis revealed predisposing hypertension of the recipient, delayed graft function, and postoperative infectious complication to be independent risk factors affecting acute T-cell mediated rejection. There were no factors associated with antibody mediated rejection in univariate analysis. In case of borderline change, univariate analysis showed that postoperative surgical complication and postoperative urological complication to be independent risk factors, however multivariate analysis revealed postoperative urological complication to be the only independent risk factor affecting borderline change (data not shown).

\section{Independent Risk Factors Affecting Graft Survival}

Univariate and multivariate analyses were performed to determine independent risk factors affecting death-censored graft survival. Although univariate analysis showed that predisposing hypertension of the recipient, graft weight, graft weight-to-recipient weight ratio, delayed graft function, postoperative infection, and rejection were risk factors affecting graft survival, multivariate analysis revealed that only graft weight-to-recipient weight ratio and rejection were independent risk factors affecting graft survival (Table 5). When the correlation of graft weight or graft weight-to-recipient weight ratio with graft survival was analyzed separately in deceased donors, no statistical significance was observed. Graft weight, but not graft weight-to-recipient weight ratio, was found to be a significant risk factor affecting graft survival in LDKT in univariate analysis ( $P=0.01$, data not shown).

\section{DISCUSSION}

The number of kidney transplantation cases in South Korea is continuously increasing, with over 2,000 cases being performed annually. Living donor transplantation contributes to the majority of the increase, since organ shortage is still a major issue [1]. Recent reports have been focused on increasing the donor pool by expanding the indication for kidney donation by means of $\mathrm{ABO}$ transplantation and ECD and DCD transplantation [3-7]. Although our experience is limited for ECD and DCD transplantation, many cases of LDKT and ABOi kidney transplantation have been performed in SNUBH up to date.

SNUBH has been one of the centers in South Korea that have performed a high proportion of kidney transplantations from living donors. In this study, the 5-year death-censored graft survival was $96.6 \%$ and the 5-year patient survival was $96.6 \%$; this is comparable to prior reports showing that 5-year graft survival was between 80 and $95 \%[12,13]$. Terasaki et al. [14] reported that spousal donors show higher survival rates than living unrelated donors and cadaveric donors. Other reports have shown that spousal donations has outcomes comparable to living related donation $[15,16]$ and that the high survival rate of spousal donor transplantation is probably related to strong emotional support. Spousal donor kidney transplantation accounted for $31.6 \%$ of all cases of kidney transplantation in South Korea in 2014. This rate increased to nearly $40 \%$ in 2018 . In SNUBH, spousal donors accounted for less than $30 \%$ of living donors. Our 1-year graft survival of $99.3 \%$ for living related donors and $98.6 \%$ for spousal donors (Fig. 2E) are comparable to outcomes from a previous report [15] showing that 1-year graft survival is $96 \%$ for living related donors and $97 \%$ for spousal donors. Our 5 -year graft survival was $97.8 \%$ for living related donors and $96 \%$ for spousal donors, comparable to $79.2 \%$ for living related donors and $86.4 \%$ for spousal donors in a previous report [16], although longer follow-up is needed. In this perspective, our overall optimal outcomes of LDKT may have been achieved in part from good outcomes of spousal donors, as our dedicated team has been involved in providing a good emotional attachment to husbands and wives.

The first ABOi-KT was performed in 2013. Since then, the proportion of ABOi-KT has risen to $31.3 \%$ in 2017 , which was higher than the national proportion of $25.6 \%$ in 2017 [1]. Kosoku et al. [17] reported a propensity score matched retrospective analysis of 66 cases of ABOi-KT over 17 years and concluded that ABOi-KT was an acceptable treatment of choice for ESRD patients even at low-volume centers. There were only 42 cases of ABOi-KT among the first 300 cases in SNUBH. However, the outcome was comparable to preceding studies. Shin et al. [18] reported that death-censored graft survival rates of $A B O i$ recipients at 1 year and 3 years were $98.6 \%$ and $98.6 \%$, and patient survival rates at 1 year and 3 years were $97.3 \%$ and $95.9 \%$, respectively. Recently, Scurt et al. [19] performed a me- 
ta-analysis and found that ABOi-KT within the first 3 years after transplantation had poorer outcomes than ABOc-KT, although equivalent outcomes were achieved at 5 years after transplantation. However, our results showed that 1-year and 3-year graft survival rates of ABOi-KT were not inferior to those of $\mathrm{ABOC}-\mathrm{KT}$. In addition, 1-year and 3-year patient survival rates of ABOi-KT were comparable to those of $A B O c-K T$. We suggest that this result might be due to strict control of preoperative anti-A/B antibody titer (under 1:8). However, our results were obtained from data with a relatively short median follow-up and small number of cases. Thus, a greater number of cases and longer follow-up are needed to compare short-term and long-term outcomes of ABOi-KT and ABOc-KT. Williams et al. [20,21] showed that HLA mismatch was a significant risk factor for graft failure in both living donors and deceased donors. However, in the present study, HLA mismatch was not an independent risk factor for graft failure $(P=0.726)$ (Table 5). Such difference in results might be due to active use of immunosuppression in the present study. Among 245 patients $(81.7 \%)$ who underwent induction therapy, 235 (78.3\%) received basiliximab.

Graft weight and graft weight-to-recipient weight ratio have been found to be significant factors for death-censored graft survival in univariate and multivariate analysis in prior reports [22-24]. Similarly, graft weight-to-recipient weight ratio was found to be an independent risk factor for death-censored graft survival in the present study. However, when the correlation between graft weight-to-recipient weight ratio and graft survival was analyzed in living donors and deceased donors separately, no statistical significance was identified. Up to date, we do not have a set $\mathrm{Gw} /$ Rw ratio used in preoperative patient evaluation. Further study with greater number of cases and longer follow up is required in order to determine the correlation between graft weight or graft weight-to-recipient weight ratio and graft survival and apply the results to the treatment process.

Postoperatively, incidence of bacterial infection and viral infection were $26.3 \%$ and $24.3 \%$, respectively. These incidences were lower than those reported in prior studies $[12,14,25]$. Urinary tract infection was the most common infection, followed by pneumonia and prostatitis. Regarding viral infection, we have previously reported our experience on $\mathrm{BK}$ virus infection in kidney transplant recipients [26]. Cumulative incidence of BK virus infection slightly increased from $6.5 \%$ to $7.3 \%$, whereas no additional graft loss or dysfunction was observed afterwards. Although the incidence increased, it was similar to the incidence range of $5.3 \%-8 \%$ reported in previous studies $[27,28]$. Stronger immunosuppression is known to inevitably cause a higher BK virus infection rate [29], but since no additional graft loss was identified despite an increased incidence of BK nephropathy over time, we suggest that our accumulated experience led to an overall adequate use of immunosuppressive therapy.

In summary, 1-year and 5-year overall death-censored graft survival rates were $99 \%$ and $96.6 \%$, respectively, comparable to outcomes of other major centers. We suggest that with careful donor selection, dedicated transplant physicians, and adequate use of immunosuppressants, low-volume centers can also stably perform $\mathrm{KT}$ and achieve good outcomes. Although we have accumulated experience with ABOi-KT, we have limited experience with expanded donors and DCD donors, who we plan to include as we broaden our focus in the near future.

\section{ACKNOWLEDGMENTS}

\section{Conflict of Interest}

No potential conflict of interest relevant to this article was reported.

\section{ORCID}

Hyoung Won Koh

Koo Kyunglim https://orcid.org/0000-0003-2721-3498

Chang Sik Shin https://orcid.org/0000-0001-7319-6057

Hyung Sub Park https://orcid.org/0000-0002-5689-6323 Jong Cheol Jeong

https://orcid.org/0000-0003-0301-7644

Sejoong Kim https://orcid.org/0000-0002-7238-9962

Dong Wan Chae https://orcid.org/0000-0001-9401-892X

Jong Jin Oh https://orcid.org/0000-0003-0448-5992

Seok-Soo Byun https://orcid.org/0000-0001-7979-9035

Taeseung Lee https://orcid.org/0000-0001-6425-5924

\section{Author Contributions}

Conceptualization: TL, DWC. Data curation: HWK, HSP, JCJ. Formal analysis: HWK, HSP, SK. Investigation: JJO, SSB. Methodology: TL, DWC. Project administration: CSS, KK. Visualization: HWK, CSS, KK, HSP. Writing-original draft: HWK, HSP. Writing-review \& editing: TL, JCJ, SK, DWC. 


\section{Additional Contributions}

We would like to thank Seoul National University Bundang Hospital transplant coordinators Su Jin Jo and Seon Young Jeon for their contribution with data collection.

\section{REFERENCES}

1. Korean Network for Organ Sharing (KONOS). 2018 Annual data report [Internet]. Seoul: KONOS; 2019 [cited 2020 Aug 10]. Available from: http://konos.go.kr.

2. Hill NR, Fatoba ST, Oke JL, Hirst JA, O'Callaghan CA, Lasserson DS, et al. Global prevalence of chronic kidney disease: a systematic review and meta-analysis. PLoS One 2016;11:e0158765.

3. Ahn C, Koo TY, Jeong JC, Kim M, Yang J, Lee J, et al. Initial report of the Korean Organ Transplant Registry: the first report of national kidney transplantation data. Transplant Proc 2014;46:425-30.

4. Yang SS, Park JB. Kidney transplantation from expanded criteria donor in Korea: it's time to have our own criteria based on our experiences. J Korean Soc Transplant 2017;31:16-24.

5. Wadei HM, Heckman MG, Rawal B, Taner CB, Farahat W, Nur L, et al. Comparison of kidney function between donation after cardiac death and donation after brain death kidney transplantation. Transplantation 2013;96:274-81.

6. Kim JM, Kim SJ, Joh JW, Kwon CH, Song S, Shin M, et al. Kidney donation after cardiac death in Korea. Transplant Proc 2011;43:1434-7.

7. Snoeijs MG, Schaubel DE, Hené R, Hoitsma AJ, Idu $M M$, ljzermans $\mathrm{JN}$, et al. Kidneys from donors after cardiac death provide survival benefit. J Am Soc Nephrol 2010;21:1015-21.

8. Kim SK, Park JH, Yoon SA, Yang CW, Jin DC, Kim SY, et al. Clinical analysis on 200 cases of kidney transplantation in a single center. J Korean Soc Transplant 2001;15:183-8.

9. Kim JS, Kim HT, Cho WH, Park SB, Kim HC, Park CH, et al. Single center experience of 500 consecutive renal transplantation. J Korean Soc Transplant 2001;15:812.

10. Hong JW, Shin MJ, Moon HH, Lee SH, Kim JM, Park $\mathrm{JB}$, et al. Analysis of 1,500 kidney transplantations at Sungkyunkwan University. J Korean Soc Transplant 2014;28:25-35.
11. Heo Y, Park HS, Shin CS, Yoo KC, Kim D, Lee T. Successful treatment of life-threatening small bowel bleeding with thalidomide after living donor kidney transplantation: a case report. Transplant Proc 2019;51:3092-8.

12. Drognitz O, Donauer J, Kamgang J, Baier P, Neeff $H$, Lohrmann $\mathrm{C}$, et al. Living-donor kidney transplantation: the Freiburg experience. Langenbecks Arch Surg 2007;392:23-33.

13. Kwon OJ, Kim YH, Ahn BK, Kang CM, Kwak JY. Longterm graft outcome of living donor renal transplantation: single center experience. Transplant Proc 2005;37:690-2.

14. Terasaki PI, Cecka JM, Gjertson DW, Takemoto S. High survival rates of kidney transplants from spousal and living unrelated donors. N Engl J Med 1995;333:333-6.

15. Roozbeh J, Mehdizadeh AR, Izadfar MA, Razmkon A, Salahi H, Malek-Hosseini SA. Comparison of spousal with other donor groups: study of a single center. Transplant Proc 2006;38:562-3.

16. Tang S, Lui SL, Lo CY, Lo WK, Cheng IK, Lai KN, et al. Spousal renal donor transplantation in Chinese subjects: a 10 year experience from a single centre. Nephrol Dial Transplant 2004;19:203-6.

17. Kosoku A, Uchida J, Nishide S, Kabei K, Shimada H, Iwai $\mathrm{T}$, et al. ABO-incompatible kidney transplantation as a renal replacement therapy: a single low volume center experience in Japan. PLoS One 2018 Dec 31 [Epub]. https://doi.org/10.1371/journal.pone.0208638

18. Shin E, Kwon SW, Yang WS, Baeck C, Yu H, Cho H, et al. Long-term outcomes of $A B O$-incompatible living donor kidney transplantation: a comparative analysis. Transplant Proc 2015;47:1720-6.

19. Scurt FG, Ewert L, Mertens PR, Haller H, Schmidt BM, Chatzikyrkou C. Clinical outcomes after ABO-incompatible renal transplantation: a systematic review and meta-analysis. Lancet 2019;393:2059-72.

20. Williams RC, Opelz G, McGarvey CJ, Weil EJ, Chakkera HA. The risk of transplant failure with HLA mismatch in first adult kidney allografts from deceased donors. Transplantation 2016;100:1094-102.

21. Williams RC, Opelz G, Weil EJ, McGarvey CJ, Chakkera HA. The risk of transplant failure with HLA mismatch in first adult kidney allografts 2: living donors, summary, guide. Transplant Direct 2017;3:e152.

22. Nicholson ML, Windmill DC, Horsburgh T, Harris KP. Influence of allograft size to recipient body-weight ratio on the long-term outcome of renal transplantation. $\mathrm{Br}$ 
J Surg 2000;87:314-9.

23. Giral M, Foucher $Y$, Karam G, Labrune $Y$, Kessler M, Hurault de Ligny $B$, et al. Kidney and recipient weight incompatibility reduces long-term graft survival. J Am Soc Nephrol 2010;21:1022-9.

24. Eo SH, Lee SH, Won JH, Oh CK. Impact of graft kidney volume and weight on graft function in living donor kidney transplantation. J Korean Soc Transplant 2015;29:209-15.

25. Pourmand G, Salem S, Mehrsai A, Taherimahmoudi M, Ebrahimi R, Pourmand MR. Infectious complications after kidney transplantation: a single-center experience. Transpl Infect Dis 2007;9:302-9.

26. Yoo YS, Park HS, Oh SW, Chae DW, Lee TS. Clinical manifestations of BK virus infection in kidney transplant recipients: a single center experience. J Korean Soc Transplant 2012;26:23-31.

27. Kim HC, Hwang EA, Kang MJ, Han SY, Park SB, Park KK. BK virus infection in kidney transplant recipients. Transplant Proc 2004;36:2113-5.

28. Hirsch HH, Knowles W, Dickenmann M, Passweg J, Klimkait T, Mihatsch MJ, et al. Prospective study of polyomavirus type BK replication and nephropathy in renal-transplant recipients. $\mathrm{N}$ Engl J Med 2002;347:488-96.

29. Bohl DL, Brennan DC. BK virus nephropathy and kidney transplantation. Clin J Am Soc Nephrol 2007;2 Suppl 1:S36-46. 